Supporting Information

\title{
Carbon Nanofibers Featuring Bimetallic Nanoparticle-in-Pore Structures as Water-Splitting Electrocatalysts
}

Eunseo Heo, ${ }^{b}$ Seonmyeong Noh, ${ }^{b}$ Hyemi Jo $^{b}$ Haney Lee, ${ }^{a}$ Sanghyuck Lee,${ }^{b}$ Minjin Kim,${ }^{b}$ Jisun Lee, ${ }^{b}$ and Hyeonseok Yoon ${ }^{a, b,{ }^{*}}$

aAlan G. MacDiarmid Energy Research Institute \& School of Polymer Science and Engineering, Chonnam National University, 77 Yongbong-ro, Buk-gu, Gwangju 61186, South Korea.

${ }^{b}$ Department of Polymer Engineering, Graduate School, Chonnam National University, 77 Yongbong-ro, Buk-gu, Gwangju 61186, South Korea.

E-mail: hyoon@chonnam.ac.kr; Fax: +82-62-530-1779; Tel: +82-62-530-1778 
Table S1. Relative contents of transition-metal and oxygen atoms in metallic, nanoparticulatecontaining carbon nanofibers (MCNFs) prepared with binary mixtures of metal species/anionic surfactant complexes (MSCs) (bMCNFs) or single MSCs (sMCNFs) (determined by transmission electron microscopy (TEM) couple with energy-dispersive X-ray spectroscopy (EDS)).

\begin{tabular}{|c|c|c|c|c|c|}
\hline \multirow[b]{2}{*}{ Sample } & \multicolumn{5}{|c|}{ Atomic ratio } \\
\hline & $\mathrm{Fe}$ & $\mathrm{Co}$ & $\mathrm{Ni}$ & Oxygen & $\begin{array}{c}\text { Oxygen: } \\
\text { Metal }\end{array}$ \\
\hline FeCoCNFs & 1 & 1 & - & 5 & $2.8: 1$ \\
\hline FeNiCNFs & 1 & - & 1 & 3 & $1.5: 1$ \\
\hline CoNiCNFs & - & 1 & 1 & 3 & $1.3: 1$ \\
\hline \multirow{2}{*}{ Sample } & \multicolumn{4}{|c|}{ Atomic ratio } & \\
\hline & Metal & & Oxygen & Oxygen:Metal & \\
\hline FeCNFs & 1 & & 4 & $2.5: 1$ & \\
\hline CoCNFs & 2 & & 4 & $2.2: 1$ & \\
\hline NiCNFs & 2 & & 3 & $1.4: 1$ & \\
\hline
\end{tabular}



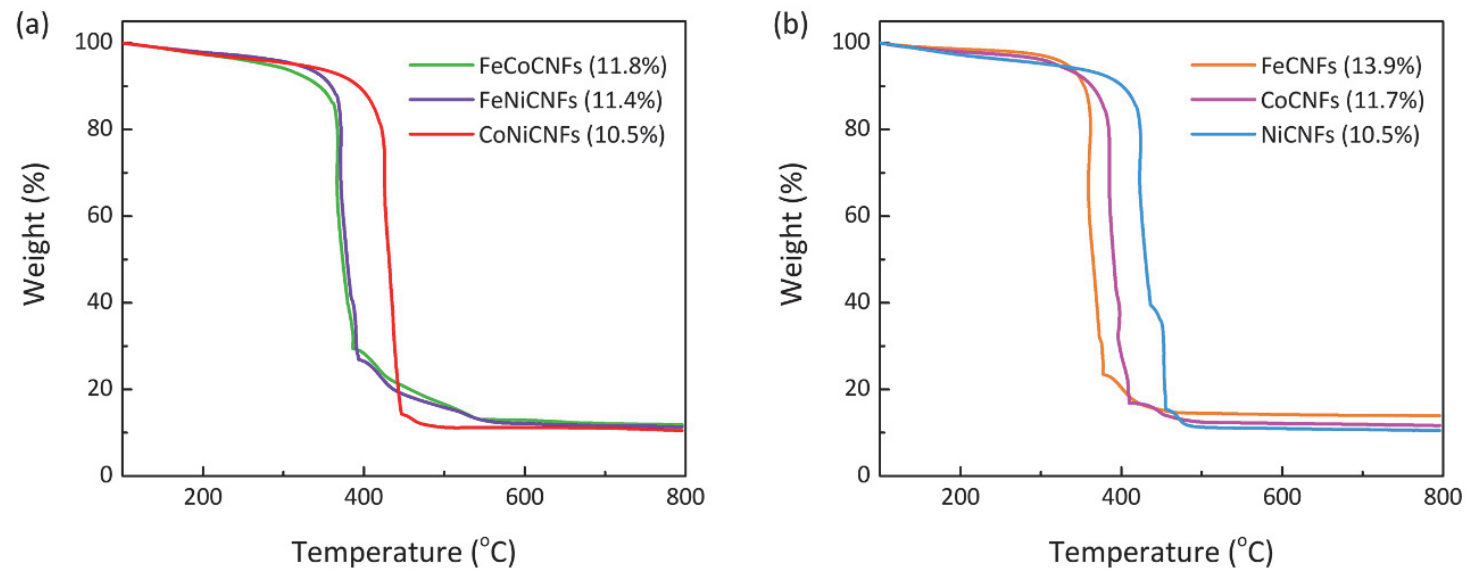

Figure S1. Thermogravimetric analysis (TGA) curves of the bMCNFs and sMCNFs recorded at a heating rate of $10^{\circ} \mathrm{C} \mathrm{min}^{-1}$ in an oxygen atmosphere. 
Table S2. Major textural parameters of the bMCNFs and sMCNFs.

\begin{tabular}{lcccccccc}
\hline Sample & $\begin{array}{c}\mathrm{S}_{\text {area }}{ }^{\mathrm{a}} \\
{\left[\mathrm{m}^{2} \mathrm{~g}^{-1}\right]}\end{array}$ & $\begin{array}{c}\mathrm{V}_{\text {total }} \\
{\left[10^{-2} \mathrm{~cm}^{3} \mathrm{~g}^{-1}\right]}\end{array}$ & $\begin{array}{c}\mathrm{V}_{\text {micro }}{ }^{\mathrm{b}} \\
{\left[10^{-2} \mathrm{~cm}^{3}\right.} \\
\left.\mathrm{g}^{-1}\right]\end{array}$ & $\begin{array}{c}\mathrm{V}_{\text {meso }}{ }^{\mathrm{c}} \\
{\left[10^{-2} \mathrm{~cm}^{3}\right.} \\
\left.\mathrm{g}^{-1}\right]\end{array}$ & $\begin{array}{c}\mathrm{V}_{\text {macro }}{ }^{\mathrm{d}} \\
{\left[10^{-2} \mathrm{~cm}^{3}\right.} \\
\left.\mathrm{g}^{-1}\right]\end{array}$ & \multicolumn{2}{c}{$\mathrm{V}_{\text {micro }} / \mathrm{V}_{\text {total }} \mathrm{V}_{\text {meso }} / \mathrm{V}_{\text {total }} \mathrm{V}_{\text {macro }} / \mathrm{V}_{\text {total }}$} \\
FeCoCNFs & 467.68 & 27.46 & 17.25 & 9.73 & 0.48 & 6.28 & 3.54 & 0.18 \\
FeNiCNFs & 505.05 & 30.44 & 18.87 & 10.86 & 0.71 & 6.20 & 3.57 & 0.23 \\
CoNiCNFs & 553.95 & 30.36 & 21.06 & 8.51 & 0.79 & 6.94 & 2.80 & 0.26 \\
FeCNFs & 382.32 & 22.24 & 15.82 & 6.01 & 0.41 & 7.11 & 2.70 & 0.19 \\
CoCNFs & 449.08 & 23.72 & 17.03 & 6.29 & 0.40 & 7.18 & 2.65 & 0.17 \\
NiCNFs & 452.18 & 24.32 & 17.54 & 6.38 & 0.40 & 7.21 & 2.62 & 0.17 \\
\hline
\end{tabular}

${ }^{\text {a }}$ Specific surface area calculated by the BET method.

${ }^{\mathrm{b}}$ Micropore volume calculated by MP method.

${ }^{\mathrm{c}}$ Mesopore $(2-50 \mathrm{~nm})$ volume and ${ }^{\mathrm{d}}$ macropore $(50-100 \mathrm{~nm})$ volume calculated by the BJH method. 

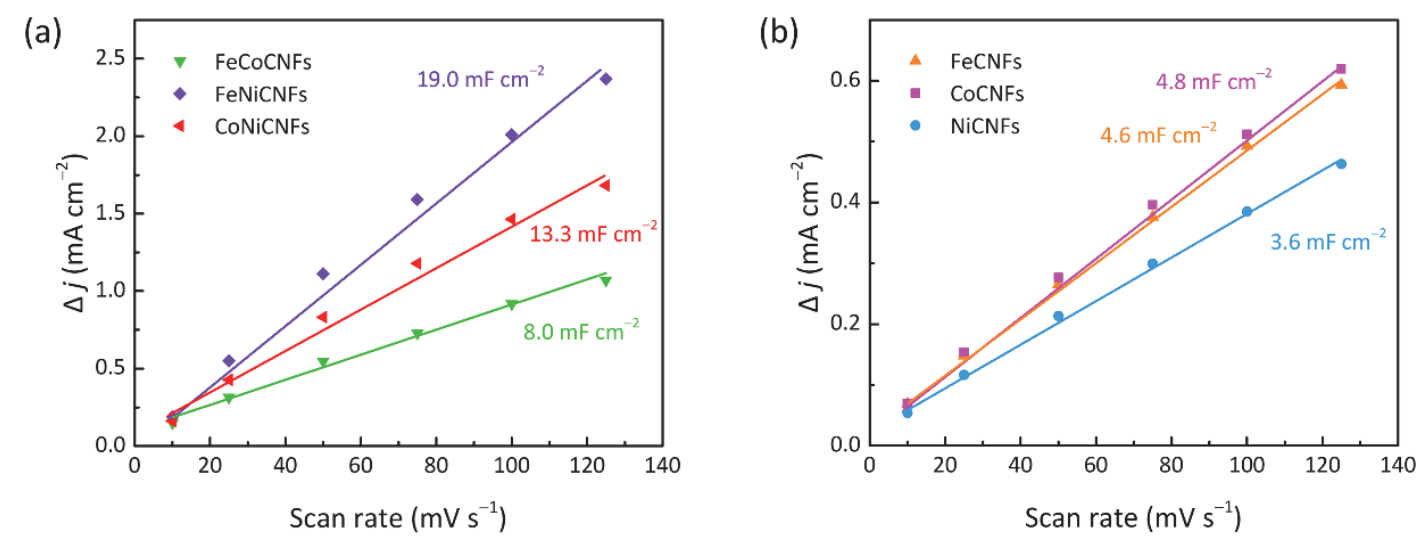

Figure S2. Capacitive $\Delta j=j_{\mathrm{a}}-j_{\mathrm{c}}$ at $1.13 \mathrm{~V}$ (vs RHE) against the various scan rates of the (a) bMCNFs and (b) sMCNFs.

The electrochemically active surface area (ECSA) of the MCNFs was calculated by estimating the double-layer capacitance $\left(C_{\mathrm{dl}}\right)$ from the cyclic voltammetry curves recorded at different scan rates in $1 \mathrm{M} \mathrm{KOH}$. The $C_{\mathrm{dl}}$ of the MCNFs, which is indicative of ECSA, increased in the order of NiCNFs $<$ FeCNFs $<$ CoCNFs $<$ FeCoCNFs $<$ CoNiCNFs $<$ FeNiCNFs. Note that the MCNFs prepared with the binary MSC mixtures exhibited larger mesopore volumes than those prepared with the single MSCs.

As a result, the bMCNFs with lower charge transfer resistances and larger ECSAs would result in better catalytic performances than the sMCNFs. 


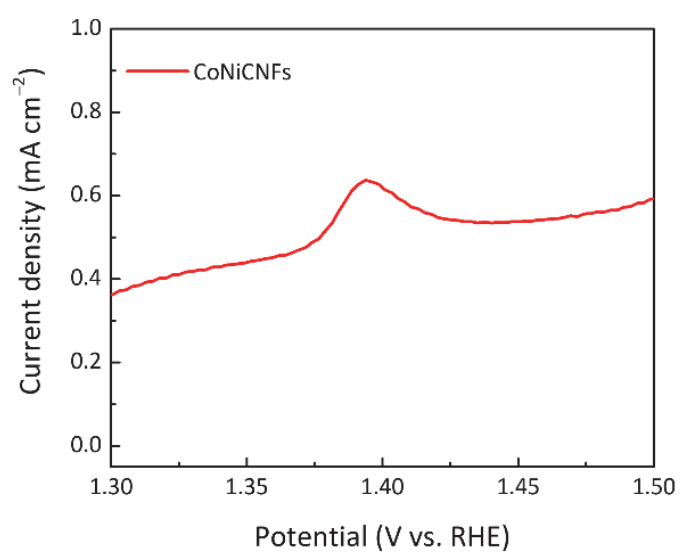

Figure S3. Linear sweep voltammetry (LSV) polarization curve of the CoNiCNFs.

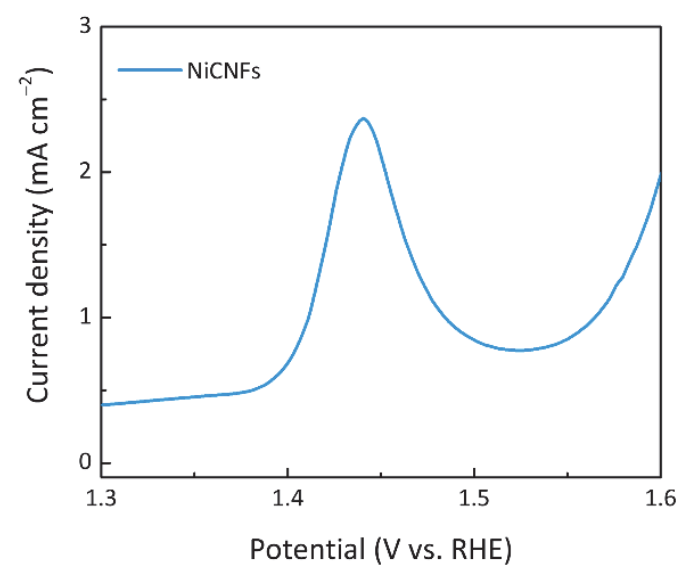

Figure S4. LSV polarization curve of the NiCNFs.

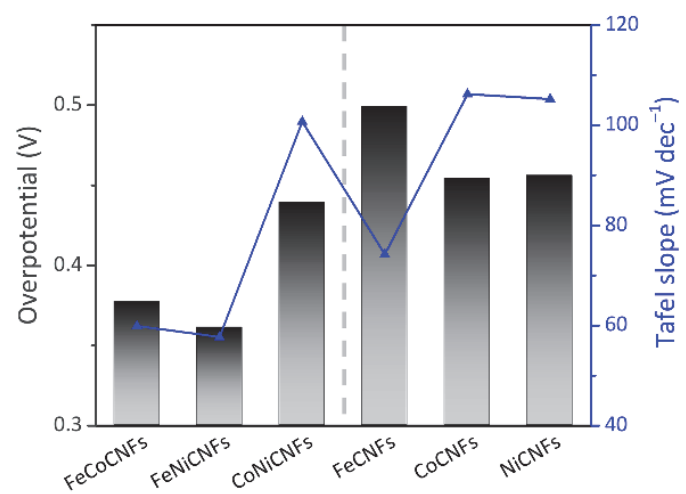

Figure S5. Overpotentials (at a current density of $10 \mathrm{~mA} \mathrm{~cm}^{-2}$ ) and Tafel slopes of the bMCNFs and SMCNFs measured for the OER. 


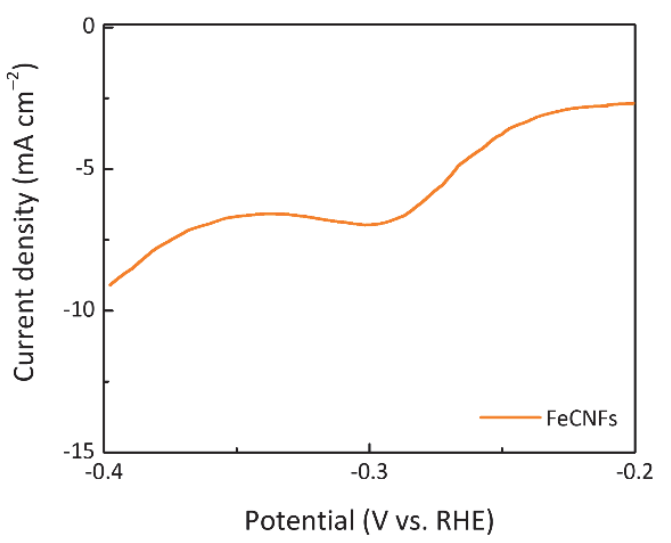

Figure S6. LSV polarization curve of the FeCNFs.

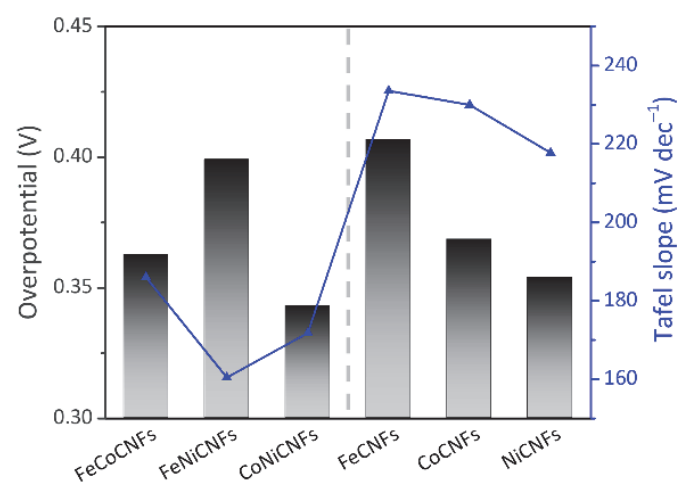

Figure S7. Overpotentials (at a current density of $10 \mathrm{~mA} \mathrm{~cm}^{-2}$ ) and Tafel slopes of the bMCNFs and sMCNFs measured for the HER. 

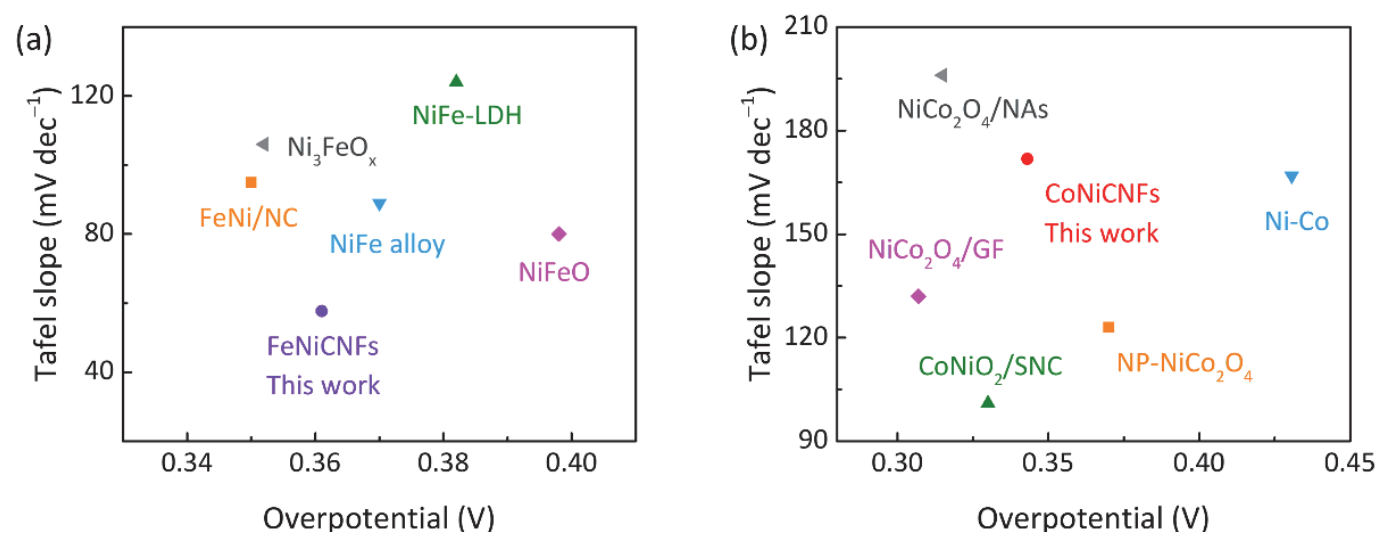

Figure S8. Plots of the major performances of similar (a) OER and (b) HER electrocatalysts for comparison (Ref. 1-10).

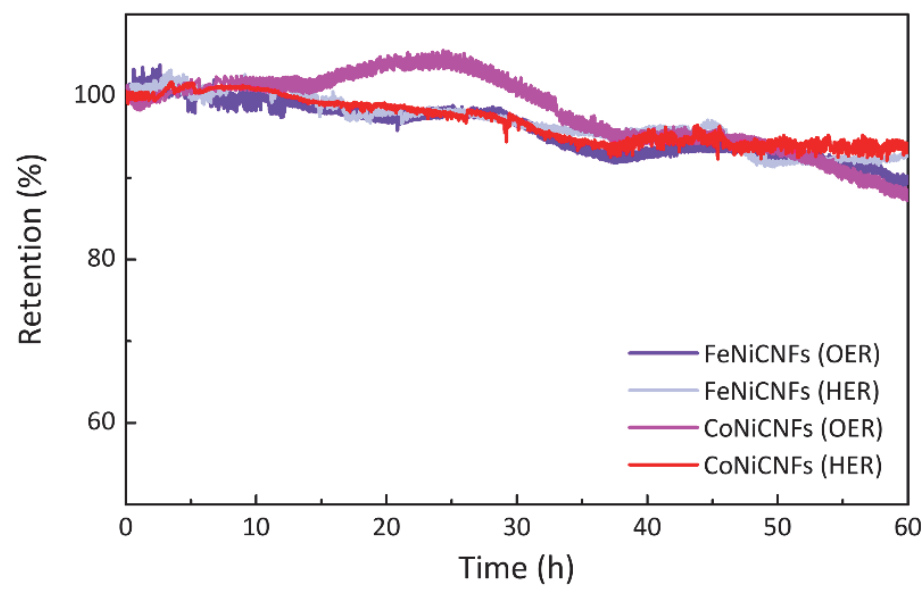

Figure S9. Long-term durability tests: chronoamperometric curves (percentage of retained current versus operation time) of MCNF electrodes for the OER and HER at potential reaching $10 \mathrm{~mA} \mathrm{~cm}^{-2}$. 

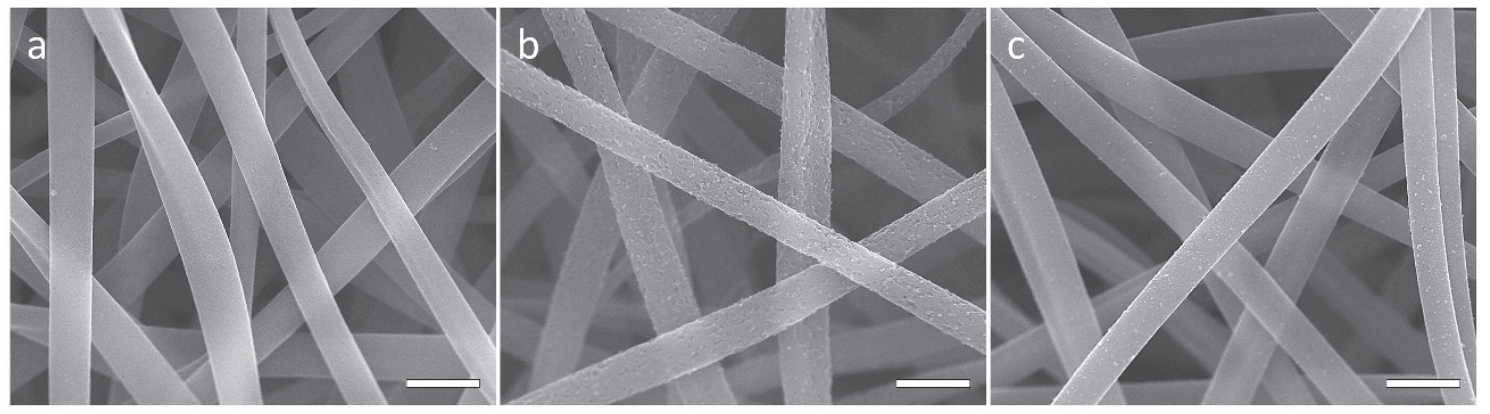

Figure S10. SEM images of the CoNiCNFs recorded (a) before and (b,c) after the long-term durability tests: (b) OER and (c) HER. The scale bar is $500 \mathrm{~nm}$.

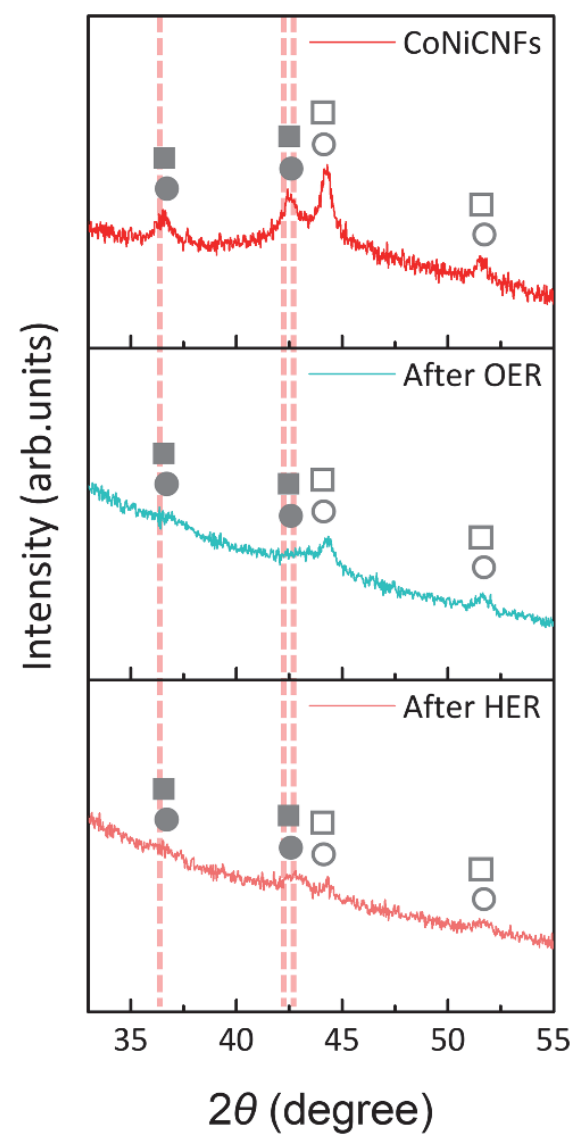

Figure S11. X-ray diffraction (XRD) patterns of the CoNiCNFs before and after the longterm durability tests (red line, $\mathrm{CoNiO}_{2}$; filled rectangle, $\mathrm{CoO}$; hollow rectangle, $\mathrm{Co}$; filled circle, $\mathrm{NiO}$; hollow circle, $\mathrm{Ni}$ ). 


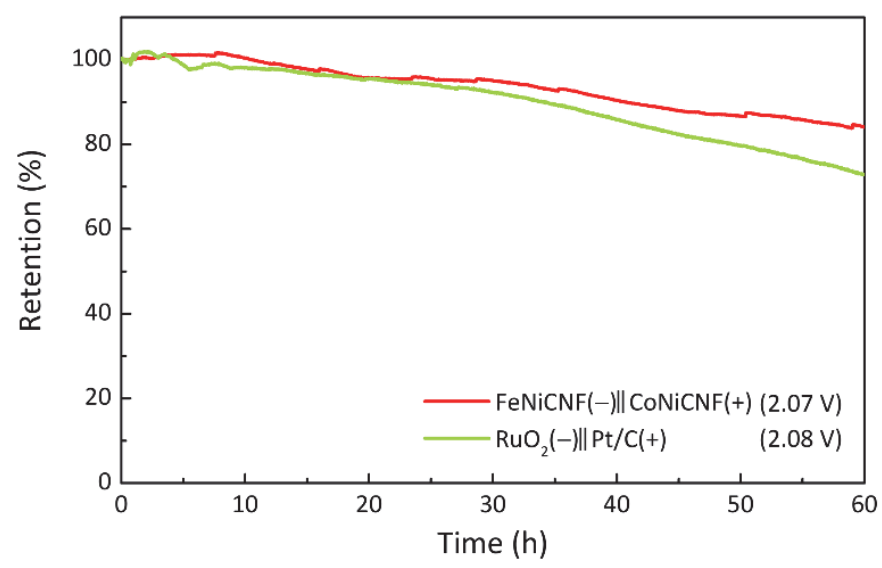

Figure S12. Current retentions of the cells monitored over $60 \mathrm{~h}$ under the voltages (provided in the parenthesis) that were required for each cell to reach a current density of $50 \mathrm{~mA} \mathrm{~cm}{ }^{-2}$ at the beginning.

After the long-term durability test, the CoNiCNF electrodes were characterized by scanning electron microscopy (SEM) and XRD. It was found that the overall morphology of the carbon nanofibers was well maintained (Figure S10), but the nanoparticulates in the carbon nanofibers appeared to degrade gradually. The intensities of the XRD peaks originating from the metal/metal-oxide phases decreased after the durability test, as exhibited in Figure S11. Note also that the current retention at higher current density $\left(50 \mathrm{~mA} \mathrm{~cm}^{-2}\right)$ was $84.2 \%$ for FeNiCNF\|CoNiCNF cell, which was better than that of $\mathrm{RuO}_{2} \| \mathrm{Pt} / \mathrm{C}$ cell $(72.8 \%)$ (Figure S12). 


\section{REFERENCES}

(1) Li, G.-L.; Xu, X.-C.; Yang, B.-B.; Cao, S.; Wang, X.; Fu, X.; Shi, Y.; Yan, Y.; Song, X.; Hao, C., Micelle-template synthesis of a 3D porous FeNi alloy and nitrogen-codoped carbon material as a bifunctional oxygen electrocatalyst. Electrochim. Acta 2020, 331, 135375.

(2) Lin, Y.; Wang, H.; Peng, C.-K.; Bu, L.; Chiang, C.-L.; Tian, K.; Zhao, Y.; Zhao, J.; Lin, Y.G.; Lee, J.-M.; Gao, L., Co-Induced Electronic Optimization of Hierarchical NiFe LDH for Oxygen Evolution. Small 2020, 16, (38), 2002426.

(3) Xie, C.; Wang, Y.; Hu, K.; Tao, L.; Huang, X.; Huo, J.; Wang, S., In situ confined synthesis of molybdenum oxide decorated nickel-iron alloy nanosheets from $\mathrm{MoO}_{4}{ }^{2-}$ intercalated layered double hydroxides for the oxygen evolution reaction. J. Mater. Chem. A 2017, 5, (1), 87-91.

(4) Dai, X.; Xin, Y.; Chen, Y.; Tan, Q.; Liu, Y., NiFe hydroxide pillared by metaborate for efficient oxygen evolution reaction. Electrochim. Acta 2021, 366, 137427.

(5) Saad, A.; Shen, H.; Cheng, Z.; Arbi, R.; Guo, B.; Hui, L. S.; Liang, K.; Liu, S.; Attfield, J. P.; Turak, A.; Wang, J.; Yang, M., Mesoporous Ternary Nitrides of Earth-Abundant Metals as Oxygen Evolution Electrocatalyst. Nanomicro Lett . 2020, 12, (1), 79.

(6) Elakkiya, R.; Ramkumar, R.; Maduraiveeran, G., Flower-like nickel-cobalt oxide nanomaterials as bi-functional catalyst for electrochemical water splitting. Mater. Res. Bull. 2019, 116, 98-105.

(7) Zhang, Q.; Han, W.; Xu, Z.; Li, Y.; Chen, L.; Bai, Z.; Yang, L.; Wang, X., Hollow waxberrylike cobalt-nickel oxide/S,N-codoped carbon nanospheres as a trifunctional electrocatalyst for OER, ORR, and HER. RSC Adv. 2020, 10, (46), 27788-27793.

(8) Dahonog, L. A.; Balela, M. D. L., Electroless Deposition of Nickel-Cobalt Nanoparticles for Hydrogen Evolution Reaction. Mater. Today: Proc. 2020, 22, 268-274.

(9) Liu, Z.; Tan, H.; Liu, D.; Liu, X.; Xin, J.; Xie, J.; Zhao, M.; Song, L.; Dai, L.; Liu, H., Promotion of Overall Water Splitting Activity Over a Wide $\mathrm{pH}$ Range by Interfacial Electrical Effects of Metallic NiCo-nitrides Nanoparticle/NiCo $\mathrm{O}_{4}$ Nanoflake/graphite Fibers. $A d v$. Sci. 2019, 6, (5), 1801829.

(10) Wang, Q.; Wang, H.; Cheng, X.; Fritz, M.; Wang, D.; Li, H.; Bund, A.; Chen, G.; Schaaf, $\mathrm{P}$., $\mathrm{NiCo}_{2} \mathrm{O}_{4} @ \mathrm{Ni}_{2} \mathrm{P}$ nanorods grown on nickel nanorod arrays as a bifunctional catalyst for efficient overall water splitting. Mater. Today Energy 2020, 17, 100490. 